\title{
Gamification and Remind App: An Applied Experience in a Professional Competencies Development Workshop
}

\author{
https://doi.org/10.3991/ijep.v10i2.11632 \\ Brenda N. Santos-Guevara $\left({ }^{\bowtie}\right)$ \\ Tecnologico de Monterrey, Monterrey, México \\ brendasantosatec.mx \\ Alejandro Acuña López \\ Tecnologico de Monterrey, Querétaro, México
}

\begin{abstract}
The design of the third workshop of the Professional Experience Modality was based on gamification, and students, most of them undergraduate engineers, were supposed to be secret agents with specific competencies to solve missions (assignments they should solve working in collaborative teams) in accordance with the course syllabus. Secret agents worked during the academic period to earn extra performance points from the missions and to receive a recognition badge as secret agents prepared for their internships.

The use of the Remind app enhances close communication between teacher and students in a simple way. Sixty-three percent of students who used the app were satisfied with it, feeling accompanied, and using the app to resolve questions about due dates, receive general instructions for assignments, and see their progressive development of competencies.
\end{abstract}

Keywords-Apps for education, Remind, educational innovation, engineering education, gamification, higher education.

\section{Introduction}

The present context of teaching and learning has a primary objective to form professionals with lifelong competencies developed during their disciplinary training because the working world demands autonomous professionals with a high level of self-management skills. In addition, universities face the challenge of finding attractive strategies to educate students. For these particular reasons, Tecnológico de Monterrey is implementing the TEC 21 Educative Model to train professionals who are internationally competitive, and who confront the future as leaders with entrepreneurial spirit and human sensitivity [1], achieved through flexible teaching plans and the appropriate application of pedagogical and technological tendencies that promote greater autonomy and involvement of the students [2].

Two considerations in particular - technology applied to education and pedagogical tendencies, and the strengthening and growth of programs of full-time professional experience for college students - emphasize the clear need for universities to contrib- 
ute to the development of students' professional competencies so that they perform optimally in activities related to their disciplines during full-time internships.

Gamification is regarded as a relevant resource for achieving these attributes in university students, and it can be applied to any area of professional formation as long as its design and implementation are planned to avoid a negative perception by both teachers and students [3].

Especially since 2013, the year in which the number of indexed publications on this topic increased considerably [3] [4] [5], several techniques to facilitate learning have been studied and documented that foster agility and dynamism in academic activities [6].

Gamification is one of the most booming educational tendencies [3], as it increases the understanding of the characteristics of education and its challenges in the $21 \mathrm{st}$ century. Applied to some skills or specific knowledge, it may increase the number of students attending classes or the number who turn in homework; however, the endusers and the course contents must always be taken into account [7].

Gamification is the use of game elements and game-design techniques in non-game contexts to engage people [8]. One can say that gamification transfers the elements of a game and its mechanisms to situations where gaming does not usually appear, such as classrooms [9]. Games offer motivation and enthusiasm for students to get involved in their learning [8][10]. Well-designed games present clear objectives, recognition (for example, badges of accomplishment), and a reward scheme.

On the other hand, the use of mobile applications to promote communication applies to both online and in-presence modalities (such as traditional classroom teaching). In the latter scenario, in-person education also requires a means of communication to facilitate teacher-student and student-student interactions as part of the development of competencies [11]. It is undeniable that the use of mobile devices is already an integral player in the social and personal performance of students in university education.

The use of apps in the classes has also become common because the communication demands on both, students and teachers, have increased and have generated a sense of urgency to obtain specific information, whether academic or non-academic. The apps simplify organization, help to answer questions in a timely manner, and accompany the students in their activities in real-time [12]. Regarding these apps, although some authors favor their use, some studies question the real impact of the use and relevance of instant messaging apps in learning.

\section{Gamification}

Gamification consists of taking elements of a game to scenarios not created for a game. A notable characteristic is its highly structured and results-oriented design for very specific processes [9]. Elements of professional competence and a system of rewards should be embedded carefully in the learning contents of a course [13]; otherwise, gamification would not have a valuable purpose. Although gamification can be applied to any area of educational performance, it must be carefully designed. The 
risk of not doing so is that the game becomes merely fun and entertaining and not a teaching strategy [13]. Once this precaution is taken, gamification can be applied to any class scenario or competency-based workshops.

\subsection{Definition of the idea}

The course in which we applied gamification had as a central objective to contribute to the development of five competencies that prepare students in the last third of their careers (disciplinary curricula) for full-time professional practice. The competencies included in the course syllabus are innovation, adaptation to change, analysis and decision-making, strategy, and negotiation. Given the definition and focus of these competencies, we decided to frame the course using a theme that would provide a touch of fun and spark interest, while also increasing the motivation and involvement of the students in the course and its assignments.

As secret agents, the students were required to complete some missions (assignments) as a team while carrying out activities that built their competencies. Integrative activities were designed for more than one competency per mission, and there were three or four missions per semester. The secret agent theme infiltrated the sixteen sessions of the course and was used in the session titles and in the presentations where the students gave evidence of their competencies. However, it is important to mention that on some occasions, the terms "secret agent" and "detective" were used synonymously, given that the competencies and the characteristics, stereotypes, of both roles were considered equivalent.

Because this course is offered to students enrolled in the Modality of Professional Experience (MEP) throughout all the careers (curricula) of the institution, the classes are composed of students earning bachelor degrees and engineering degrees in various majors. Through the theme of the course, we sought the involvement of students from both degree programs to develop the competencies intended in the course. The secret agent theme was used because it was considered a common denominator to which all the students could relate no matter their discipline.

\subsection{Implementation of gamification and adjustments}

The implementation of the theme was carried out in fourth academic periods (semesters), and the modifications and adjustments were primarily in the content of the missions and the class presentations (content and explanation of the topic). In the beginning, the issue of units (sets of secret agents) and squadrons referred to in collaborative work were addressed interchangeably. However, as the periods and the implementation advanced, the concept that squadrons would have sub-units was integrated into the activity assignments. Table 1 shows the different types of modalities possible to perform a task.

The main feature of the squadrons is that these teams worked on assignments and missions during the semester, while the subunits were teams who performed assignments during one class. 
Beginning with the second semester, the teachers presented the course context in the introductory session, explaining that the students had been selected from a special group that would form a unit "whose objective was" to contribute to the special agents who make up the InteliMEPcia headquarters. In this introduction, the teachers told the students that they should reflect on the importance of the development of professional competencies required in their fields of expertise for the internships they would seek.

In periods 2 to 4 , the squadrons were assigned according to the three competencies that most interested each student. Once assigned to squadrons, the students learned that each squadron would be responsible for the closing activity of each assigned competency and that they would have to suggest activities that their other classmates, in turn, would deliver as evidence of the competency. In this way, we reinforced the involvement of the students (agents) and their commitment to the competencies of the course.

The assigned roles gave students more autonomy and let the teacher be a facilitator. Therefore, the teacher, as chief, presented the cases (the subjects and missions) that the students had to solve as special agents.

For the reward system, the results of each mission were evaluated according to rubrics and established criteria. For the most part, the completion of these missions gave extra credit opportunities. We named insignias (badges) corresponding to each point obtained for the resolution of a component of the mission. Some of the evaluation criteria for awarding insignias (badges) included, but were not limited to, compliance with the requirements of delivery, punctuality, format, quality of content, and creativity. The extra points available were variable in each mission and semester.

At the end of the course, each student received his/her printed Special Agent insignia, indicating that they were prepared to carry out his/her professional stay. At the time that the final evaluations were shown, it was revealed which squadrons had obtained the insignias (extra points).

The feedback system for the gamification consisted mainly of the perceptions of the teaching team and the comments from the students at different mark points of the course during the first three periods in which this subject was taught. Additionally, in the last two periods, we administered a brief survey at the end to measure the course satisfaction and receive suggested modifications. The survey responses led to adjustments at the beginning of the subsequent period.

Table 1. Modalities of delivery of carrying out of activities

\begin{tabular}{|l|l|}
\hline \multicolumn{1}{|c|}{ Type } & \multicolumn{1}{c|}{ Description } \\
\hline Agent & Each student was a secret agent who could do individual work. \\
\hline Subunit & $\begin{array}{l}\text { Small group integrated to work together only in the current session. In other sessions, the team } \\
\text { members are different. }\end{array}$ \\
\hline Squadron & $\begin{array}{l}\text { Semester- integrated work team. The main objective was solving assigned missions together } \\
\text { throughout the semester. }\end{array}$ \\
\hline
\end{tabular}

Based on the requirements of the modality program and the feedback from students, from Period 3 on, we added topics that would help the students prepare for the search of their internships (hiring process). 
This led to an increase in the number of graded activities. With the aforementioned modifications, the secret agents were less consistent with the objectives of the workshop, despite the fact that the professional competencies remained the same. In addition, we gave a different role to the squadrons. From that moment, they no longer only had to complete the missions, but they must also prepare the closing session of the assigned competency, providing examples of the achievements in their e-portfolios. In this way, the insignias (badges) were assigned according to personal performance (as an agent) combined with the results obtained by the team (squadron). At this time, far from providing motivation and commitment of students to the course, gamification has been perceived by them as an extra burden, or what Rabah et al. describe as an additional stress factor [9]. In this period, we observed that one of the objectives of the gamification was altered because it was not focusing on the development of the competence and the process itself [13].

\subsection{Remind app use}

The feedback about the course indicated that one of the most significant difficulties the students faced during the course was communication. For that reason, in period 4, we introduced the use of the Remind app as an optional tool of communication in addition to the traditional pathways for the course (the Blackboard platform and email).

The use of this application was voluntary and was not assessed as part of the course; however, it was used to encourage communication between students and the teacher in a practical and immediate way [14]. The second intention for the use of Remind was to clarify questions about the activities and to send periodic reminders about their assignment completion dates, as well as the specification of the type of delivery that was required (collaborative or individual). Therefore, the students received the class code in the first session of the semester and were invited to join the class using their preferred (email or mobile) device.

We chose this app based on the advantages it offers over other tools or apps such as WhatsApp or text messaging. The Remind app does not ask the user to share personal information. This feature allows communication to remain professional, restricted, and instantaneous. Each user can see the information about the days and hours of attention in which they can receive a response to their messages. To maintain the privacy of each user's data, we generated a class code and sent the invitation to join through a link in Blackboard. Each user can choose the device of their choice to connect. Another advantage of this app is that it can be used via email, web (direct from the Remind site) or from the smartphones if the user downloads the app to his/her phone. From the app, you can send "public announcements" to the whole class or private messages to one or several users. Among other features, it allows the user to send files, and it can be used like any text messaging app. 


\section{$3 \quad$ Analysis of Results}

Gamification is a valuable resource for developing autonomy and independence among the students, and its application is increasingly more frequent in scenarios beyond the classroom [15]. The theme of "secret agents" was implemented under the pretext of the analytical program based on the five central competencies of the course, since it was considered that these competencies are characteristics of analytical people who can make decisions and propose strategies according to the environment or situation presented to them (adaptation to change).

In the first stage, the students were enthusiastic about the new approach of the course. While the teaching team also showed their enthusiasm for the topic, the implementation aimed primarily at the design of the sessions and the presentations in each class. Students expressed that one of the moments they most looked forward to in the class was knowing the name of each session. They reported that the title of each session helped them to remember the content of each class because they could associate it to the professional competence of the class. Each competency generally was allocated among two to three sessions, and one session for some of the missions that took place during the semester.

According to the requirements of the program (Modality) and the feedback from students, from Period 3 on, we added topics related to preparing students for their internship searches (hiring process). This also involved an increase in the number of graded activities. With the aforementioned modification, the secret agents were less consistent with the objectives of the workshops, despite the fact that the professional competencies remained the same. As the number of graded activities increased, as shown in Table 2, the individual work weighed more heavily on the students than the collaborative work, so squadrons were not as supportive to the students as intended.

The individual vs. collaborative work generated confusion among the students at different times, particularly in the academic periods in which the number of activities increased due to the need for additional preparation in other subjects that required individual work, such as preparing for a mock interview or a CV. Therefore, it was unclear to the students whether the theme (Secret Agents) related to the work they were doing individually or collaboratively.

Due to the number and extension of the assignments, the students stopped participating in the subject matter and limited themselves to working on their assignments for their evaluations. Individual contributions became integrated into the collaborative work, and, consequently, the gain of additional points did not represent a sufficient incentive to encourage participation in the subject; i.e., students abandoned the role of secret agents and squadrons to complete their activities without them. 
Table 2. Characteristics of classes and periods in which the secret agent theme was used in gamification

\begin{tabular}{|l|c|c|c|}
\hline & Period 1 & Period 2 & Period 3 \\
\hline Number of students per class & 16 & 24,27 & $24,31,5$ \\
\hline Number of graded activities & 16 & 25 & 22 \\
\hline Number of missions & 3 & 4 & 4 \\
\hline General final average grade & 96 & 79,94 & $98,97,98$ \\
\hline $\begin{array}{l}\text { The main response from students } \\
\text { feedback }\end{array}$ & $\begin{array}{c}\text { The secret agent theme } \\
\text { was fun. }\end{array}$ & $\begin{array}{c}\text { An excessive number } \\
\text { activities. Confusion } \\
\text { in the work system. }\end{array}$ & $\begin{array}{c}\text { The students preferred to } \\
\text { be helped to prepare for } \\
\text { the search for profession- } \\
\text { al stays. }\end{array}$ \\
\hline
\end{tabular}

In addition, we have given a different role to the squadrons. Now, the students not only have to complete the activities but also they must prepare the closing session of the assigned competency, providing examples of the achievements in their eportfolios. In this way, the insignias (badges) have been assigned according to personal performance (as an agent) and combined with the result obtained by the team (squadron). Thus, far from providing additional motivation and commitment of students to the class, gamification has been perceived as an extra burden or what Rabah et al. describe as an additional stress factor [9]. At this time, we have observed that one of the objectives of the gamification was not achieved because it was not focusing on the development of the competence and the process itself [13].

Not only that, the students did not demonstrate sufficient dominance of the competency in their oral presentations of the assigned competence during the squadron closings. In other words, although students were able to express the different definitions and attributes of each competency, they were not always able to identify the activities they could suggest to their peers to demonstrate evidence of dominance.

At the end of the first two periods, the students were asked to suggest improvements or provide feedback for the course anonymously. Sixty percent of the comments mentioned that, although the topic seemed all right to them, they wanted more dynamism in class. They preferred activities to be shorter in order to have a formal closure of each session. In the second period, the comments regarding the quantity and extension of activities gave way to aspects to improve the course. Referring to the subject matter (secret agents), the students only mentioned that it seemed okay; however, there were no comments made that the topic brought them some improvement or facilitated their carrying out of the activities. Nevertheless, the final average of the groups was around 96 to 97, as can be seen in Table 2 .

Notably, in the third period, one comment did mention specifically that the Secret Agents theme should be eliminated, because they did not understand what it was or what they should complete. In this same period, when asked which was the most useful activity, the answer given by most of the students was the brainstorming of ideas (worked in subunits), followed by negotiation activity (carried out in subunits), and, finally, the issue of establishing decision-making priorities (individuals). In none of the comments or selection of activities did they highlight the missions carried out in squadrons or even some of the activities related to the gamification. 
In period 4 , the subject of secret agents became merely the pretext for carrying out missions related to project management. In addition to this, students were less motivated to get insignias (badges) because they had to do a lot of activities for the class. During the last gamified period, insignias (badges) represented a lower benefit than in the previous periods. This was the reason why we decided to award insignias (badges) when students attended events organized by the university related to employability.

At the end of each period, the teaching team pondered the desirability of continuing the theme. With regard to the recommended specifications for gamification by Kim [5], it was understood that the central intention was to generate a feeling of more belonging and commitment by the students to the course. However, the objective was not being achieved at this point, and the reward system was not working, either, as assumed - that the students would want to earn the extra points - as Lee et al. predicted [10]. While students showed interest in the extra points, there was no difference in their interest and participation when the gamification rewards system was unlinked.

Taking these aspects into consideration, particularly comments from period 3 and the number of activities to be assessed per semester, we determined to leave only some aspects of the gamification design within the course. Moreover, at this point, we decided to reinforce communication through the use of the "Remind" app because the students expressed that they wanted more contact to resolve their questions.

Table 3 shows comments made by students on the institutional evaluations of the teachers in each period. It is important to clarify that the scale of institutional evaluation changed from Period 2 going forward. In Period 1 the optimal evaluation was one that approaches zero, while from Period 2 forward, the highest evaluation is ten. In Table 3, one can observe that in Period 5, the opinion of the students favored the criterion of "methodology and learning activities."

The perception of the students is not very variable (Table 3). However, in Period 3, there is a decline in the first two criteria, while the level of intellectual challenge, on average, has been increasing over time. The general average per group has remained similar in the five periods; this can be interpreted that even with variations in the content and number of activities, gamification has not represented a benefit nor a deficit in academic achievement, especially considering the final grades obtained by the students of the workshop.

The decision to use the Remind app was mainly due to the advantages it offers over other media and email. One of the main reasons also was that it did not require providing personal data by either side. Instead, students were provided with the code to join the class, and they also received an invitation to join the institutional email.

The use of the application was optional, and $73 \%$ of the students registered in the app once they were provided with the class code. Only one student decided not to access the class through any device. The use of the Remind app has not replaced the official means of communication. We use the Blackboard platform to host our courses. Therefore, if the students decide not to use the app, it has no negative implications.

The decision to use the Remind app was mainly due to the advantages it offers over other media and email. One of the main reasons also was that it did not require providing personal data by either side. Instead, students were provided with the code to join the class, and they also received an invitation to join the institutional email. 
The use of the application was optional, and $73 \%$ of the students registered in the app once they were provided with the class code. Only one student decided not to access the class through any device. The use of the Remind app has not replaced the official means of communication. We use the Blackboard platform to host our courses. Therefore, if the students decide not to use the app, it has no negative implications.

Although in the course evaluation, $63 \%$ of the total population reported using the application, and $78 \%$ found it useful, Table III illustrates that between periods 4 and 5 , the interaction between the students and the teacher barely increased on average, 0.23 points. One reason for this is that most of the students used email to convey questions or express comments and did not do so through the app, which altered the immediacy of the communication [16].

The interaction in the Remind app has not produced conclusive results, so we cannot say that its use represents a benefit in communication and the perception of the closeness demanded by students in this course. The use of apps to promote the closeness between teacher and pupil is very appreciated by students because they feel they are accompanied and have access to course information in a simple, practical, and instantaneous way [12].

Students who contacted the teacher through the app used it outside of class to clarify questions about activity instructions and completion dates, a good use of mobile technologies [17]. During this period, there were no comments by students about the need for greater communication or the need to clarify the activity instructions or the delivery dates, even with the low percentage of students using the app. The interactions with the teacher increased in part due to the use of the app, because they received notifications via e-mail, facilitating their contact with the teachers.

The good news is that, in Period 4, the elements of gamification were no longer additional stress for the students, because they could only get badges for specific activities outside of the classroom, such as employability events. This change caused an increase in the average of the criterion "methodology and learning activities" of 0.705 points.

At the end of this period, the comments continued referring to the need to be prepared for things that would serve them in their search for professional stays, such as $\mathrm{CV}$ preparation and mock interviews. In this way, the anxious comments and questions about activity instructions and dates of delivery decreased. The gamification and use of apps such as Remind work for both, students and teachers, allowing them to play different roles during learning and have the benefits of immediate rewards [11].These rewards can be an instant response through an app, feedback, or an act that generates a positive impact on the students.

In Period 5, we decided to preserve the concept of badges for performance or outstanding performance during the course, but the use of the Remind app was eliminated. Table III shows the effects of these decisions. There is an increase in all three criteria related to teacher evaluation.

One failure of this implementation was that the conditions and considerations of the gamification were not fully specified. When the content of the course increased, it became disconnected from the theme of Secret Agents, and no timely adaptation was made. 
Paper-Gamification and Remind App: An Applied Experience in A Professional Competencies ...

Table 3. Results and comments of students in the institutional course evaluation

\begin{tabular}{|c|c|c|c|c|c|}
\hline & Period 1 & Period 2 & Period 3 & Period 4 & Perio \\
\hline $\begin{array}{l}\text { Methodology and learning } \\
\text { activities }\end{array}$ & 1.62 & 8.65 & 8.1 & 8.81 & 9.27 \\
\hline $\begin{array}{l}\text { Teacher interaction and advice } \\
\text { during the student learning } \\
\text { process }\end{array}$ & 1.42 & 9.3 & 9.11 & 9.35 & 9.50 \\
\hline Level of intellectual challenge & 1.69 & 7.1 & 8.13 & 8.67 & 9.17 \\
\hline \multicolumn{6}{|c|}{ Comments from students in the institutional teacher evaluation: } \\
\hline Period 1 & \multicolumn{5}{|c|}{$\begin{array}{l}\text { "In this class, you learn with dynamic and unwritten activities or with } \\
\text { homework." } \\
\text { "It is necessary to structure the course so that it is useful and not boring } \\
\text { and difficult to apply during the internship." } \\
\text { "Excellent work methodology." } \\
\text { "The teacher inspires a lot of serenity." }\end{array}$} \\
\hline Period 2 & \multicolumn{5}{|c|}{$\begin{array}{l}\text { "Good relationship between classroom activities and real life. The teacher } \\
\text { clearly explains the concepts to practice in class and homework and activi- } \\
\text { ties." } \\
\text { "The class is fun." } \\
\text { "Boring, without interest." } \\
\text { "Dynamic and fun classes." } \\
\text { "I do not feel that the class has been useful." } \\
\text { "The class was very boring, and although the topics were interesting, the } \\
\text { class became tedious. Also, sometimes, everything was very confusing, } \\
\text { and I was always full of questions." }\end{array}$} \\
\hline Period 3 & \multicolumn{5}{|c|}{$\begin{array}{l}\text { "The teacher needs to make things simpler; her material is good and vast, } \\
\text { but it is not understandable." } \\
\text { "I do not like the detective theme that the class has because, with all the } \\
\text { name changes in Blackboard, it only gets confusing; it's something that } \\
\text { does not matter, and it's just extra work. In my opinion, we should do more } \\
\text { activities that develop our competencies." } \\
\text { "The class tries to be very dynamic and with good activities." } \\
\text { "The teacher applies the concepts in daily life." }\end{array}$} \\
\hline Period 4 & \multicolumn{5}{|c|}{$\begin{array}{l}\text { "The class was not as dynamic as expected." } \\
\text { "The material that we saw in class has been very useful for me to develop } \\
\text { my personal brand." } \\
\text { "Class is entertaining, and activities have great value." }\end{array}$} \\
\hline Period 5 & \multicolumn{5}{|c|}{$\begin{array}{l}\text { "Good tips on how to look for a job; she also gives classes in a very con- } \\
\text { cise way; there is no need to leave the subject." } \\
\text { "The class was very practical." } \\
\text { "It feels like the class is forced." } \\
\text { "Good class." }\end{array}$} \\
\hline
\end{tabular}

These results make us consider the possibility to combine, or even change, the pedagogical technique with game-based learning (GBL) activities to measure the impact of dynamic and fun activities on a real engagement [18]. One of the first steps to this migration should be the inquiry of theme as a secret agent for a student.

We also consider the implementation of leaderboard to enhance motivation between students; it could be as an agent by themselves or as squadrons (teams). This may increase motivation when students are allowed to see their progress in badges as a contest, or as mentioned by Hanus and Fox in a study where was found students who viewed their badges where more willing to participate and improve their perfor- 
mance [19]. The measurement of the next results will show us where there are needs for change for specific activities or the class content.

However, the current proposal is to maintain direct communication with the students through an app that allows the exchange of instant messages and integrates some phases of the gamification, which, at the moment, is disconnected from the theme of Secret agents. This communication tool also will increase motivation for students who will have the belonging feeling [20] and accompaniment. As soon as these phases have been consolidated and measured, it will be possible to evaluate the integration of the theme in the course as a central axis.

\section{Conclusion}

Everyday technologies and didactic tendencies based on the characteristics of today's students are continuously developed and assessed to improve the commitment of the students and the learning processes. However, in this research project, the results from the evaluation of the teachers were inconclusive to support the use of the Remind app or to justify gamification. This means that it is necessary to work on a proposal that integrates the most outstanding experience of each of the periods described above and strengthen the gamification design phase in a way that it truly relates to the course content. It is also important that we find a communication tool that really supports students at the right time. In our experience, we see email as a tool that hinders the rhythm of communication desired by students. On the other hand, it is possible that students find the Remind app useful for other reasons. Therefore, we propose to integrate its use as part of the class and maybe part of the activities.

The implementation of gamification requires an easy-to-understand system by students and an easily executable plan for teachers. We suggest a differentiation in the system of points that can be allocated for each phase of the gamification, for example, points for participation or some particular achievement [2]. A full understanding of the course, its contents, and consideration of the end-users are necessary at the time of designing the gamification [5].

As future steps, we propose to retain some parts of the gamification, such as the system of rewards based on performance, without forcing the theme of Secret Agents in the development of the sessions and the collaborative assignments. At the time, we consider to use an app to approach communication with students who can feel together as part of a group and motivated for active participation.

We must not put aside the purpose of the course, which, in this case, is to contribute to the preparation of the students for professional practice. Therefore, it will be necessary to strengthen the strategy of gamification in the course to emphasize competencies, so that at the end of it, students have more tools to demonstrate the mastery of their professional competencies at the time they are searching for their internships. 


\section{Acknowledgement}

The authors would like to acknowledge the financial and the technical support of Writing Lab, TecLabs, Tecnologico de Monterrey, Mexico, in the production of this work.

\section{References}

[1] "EduTrends Radar 2017”, 2017.

[2] C. González y M. Area, "Breaking the Rules : Gamification of Learning and Educational Materials 2 Gamification Proposal of Digital Educational Materials”, núm. 2013, pp. 4753.

[3] D. Dicheva, C. Dichev, G. Agre, y G. Angelova, "Gamification in Education: A Systematic Mapping Study”, vol. 18, pp. 75-88, 2015.

[4] L. Schuwirth y J. Ash, “Assessing tomorrow's learners: In competency-based education only a radically different holistic method of assessment will work. Six things we could forget", Med. Teach., vol. 35, núm. 7, pp. 555-559, 2013.

https://doi.org/10.3109/0142159X.2013.787140

[5] B. Kim, "Designing Gamification in the Right Way", Libr. Technol. Rep., vol. 51, núm. 2, pp. 29-36, 2015.

[6] D. Dicheva, K. Irwin, y C. Dichev, "OneUp: Supporting Practical and Experimental Gamification of Learning", Int. J. Serious Games, vol. 5, núm. 3, pp. 5-21, 2018.https://doi.org/10.17083/ijsg.v5i3.236

[7] K. Seaborn y D. I. Fels, "Gamification in theory and action: A survey", Int. J. Hum. Comput. Stud., vol. 74, pp. 14-31, 2015. https://doi.org/10.1016/j.ijhcs.2014.09.006

[8] G. Nistor y A. Iacob, "The Advantages of Gamification and Game-Based Learning and their Benefits in the Development of Education", J. Educ. Technol. Soc., vol. 18, núm. 4, pp. 486-497, 2015.

[9] J. Rabah, R. Cassidy, y R. Beauchemin, "Gamification in education: Real benefits or edutainment?”, Eur. Conf. eLearning, núm. May, pp. 1-6, 2018.

[10] J. J. Lee y T. College, "Gamification in Education: What , How , Why Bother? Gamification in Education: What , How, Why Bother?", núm. May, 2014.

[11] E. Vázquez-cano, "Mobile Distance Learning with Smartphones and Apps in Higher Education", vol. 14, núm. 4, pp. 1505-1521, 2014. https://doi.org/10.12738/estp.2014.4.2012

[12] Y. Sung, K. Chang, y T. Liu, "Computers \& Education The effects of integrating mobile devices with teaching and learning on students' learning performance: A meta-analysis and research synthesis", Comput. Educ., vol. 94, pp. 252-275, 2016. https://doi.org/10.10 16/j.compedu.2015.11.008

[13] İ. Yıldırım, "Students' perceptions about gamification of education: A Q-method analysis", Egit. ve Bilim, vol. 42, núm. 191, pp. 235-246, 2017. https://doi.org/10.15390/EB.2017.6970

[14] M. M. Ujakpa, D. Heukelman, V. K. Lazarus, P. Neiss, y G. D. Rukanda, "Using WhatsApp to Support Communication in Teaching and Learning", 2018 IST-Africa Week Conf., p. Page 1 of 6-Page 6 of 6, 2018. 
[15] J. A. Attenborough y S. Abbott, "Leave Them to Their Own Devices : Healthcare Students ' Experiences of Using a Range of Mobile Devices for Learning . Healthcare Students ' Experiences of Using a Range of Mobile Devices for Learning", pp. 0-10.

[16] C. Pimmer y P. Rambe, "The inherent tensions of 'Instant Education': A critical review of mobile instant messaging”, Int. Rev. Res. Open Distance Learn., vol. 19, núm. 5, pp. 219237, 2018. https://doi.org/10.19173/irrodl.v19i5.3765

[17] A. Msungu y W. P. Mtega, "Using Mobile Phones for Teaching and Learning Purposes in Higher Learning Institutions : the Case of Sokoine University of Agriculture in Tanzania", núm. January 2012, 2015.

[18] Z. Alaswad y C. Hargrave, "A game-based design studio: An exploration of an interior design studio environment for implementing game-based learning”, 2017.

[19] M. D. Hanus y J. Fox, "Assessing the effects of gamification in the classroom: A longitudinal study on intrinsic motivation, social comparison, satisfaction, effort, and academic performance", Comput. Educ., vol. 80, pp. 152-161, 2015. https://doi.org/10.1 016/j.compedu.2014.08.019

[20] C. Pimmer, R. Abiodun, F. Daniels, y J. Chipps, “'I felt a sense of belonging somewhere'. Supporting graduates' job transitions with WhatsApp groups", Nurse Educ. Today, vol. 81, núm. November 2018, pp. 57-63, 2019. https://doi.org/10.1016/j.nedt.2019.06.010

\section{$7 \quad$ Authors}

Brenda N. Santos-Guevara is professor of Professional Experience Department of the Life and Career Center of Tecnologico de Monterrey, Monterrey Campus since 2012. Her current doctoral thesis is in the topic of professional competencies. Email: brendasantos@tec.mx

Alejandro Acuña López is full-time professor in Architecture, Art and Design School of Tecnologico de Monterrey Querétaro Campus, since 2005. Research areas: Design Education and Educational Innovation. Email: aacuna@tec.mx

Article submitted 2019-09-06. Resubmitted 2019-10-14. Final acceptance 2019-10-17. Final version published as submitted by the authors. 